\title{
Chronic Intractable Pruritus in Chronic Kidney Disease Patients: Prevalence, Impact, and Management Challenges - A Narrative Review
}

\author{
Karolina Świerczyńska $\mathbb{D}$ \\ Rafał Białynicki-Birula (D) \\ Jacek C Szepietowski (D) \\ Department of Dermatology, \\ Venereology and Allergology, Wroclaw \\ Medical University, Wroclaw, Poland
}

\begin{abstract}
Chronic kidney disease (CKD) is recognized as a leading public health problem and causes numerous health complications. One of the most common and burdensome dermatological symptoms affecting patients undergoing dialysis is CKD-associated pruritus (CKD-aP). This condition not only has a negative impact on sleep, mood, daily activities, and quality of life but also increases the mortality risk of hemodialyzed patients. Despite that, this condition is greatly underestimated in clinical practice. Due to the complex and still not fully understood etiopathogenesis of CKD-aP, the choice of an effective therapy remains a challenge for clinicians. Most common therapeutic algorithms use topical treatment, phototherapy, and various systemic approaches. This review aimed to summarize most recent theories about the pathogenesis, clinical features, and treatment of CKD-aP.

Keywords: chronic kidney disease, chronic kidney disease-associated pruritus, treatment
\end{abstract}

\section{Introduction}

Chronic itch (CI) is an uncomfortable sensation that causes a desire to scratch and lasts $>6$ weeks. In contrast to acute itch, which is regarded as a defense mechanism, $\mathrm{CI}$ occurs in many skin conditions and systemic diseases. The International Forum for the Study of Itch (IFSI) expert group created the classification of CI, basing it on the etiology of pruritus. They distinguished causes of CI as cutaneous (I), systemic (II), neurological (III), psychogenic (IV), mixed (V), and other (VI). ${ }^{1}$ Over the whole range of systemic disorders occurring with itch, special attention should be paid to chronic kidney disease (CKD). This condition was defined in 2002 by the National Kidney Foundation as an abnormality of kidney structure or function presenting at least for 3 months and having implications for patients' health. ${ }^{2}$ The prevalence of CKD is about $13 \%$, and it is recognized as a leading public health problem. ${ }^{3,4} \mathrm{CKD}$ has a broad spectrum of complications, of which cutaneous manifestations play a great role. Changes in skin color, elastosis, ecchymoses, xerosis, and uremic frost, as well as perforating disorders, metastatic calcification, or bullous dermatosis, are often observed in end-stage renal disease (ESRD). ${ }^{5}$ One of the most common and burdensome dermatological symptoms affecting patients undergoing dialysis, described for the first time in 1932, is CKD-associated pruritus (CKD-aP). The nomenclature of this condition has changed over the years. Originally "uremic pruritus" was a common definition for itch associated with CKD. However, due to a lack of dependence between uremia and this sensation,
Correspondence: Jacek C Szepietowski Department of Dermatology, Venereology and Allergology, Wroclaw Medical University, I Chalubinskiego Street, Wroclaw, 50-368, Poland

Tel +48 60I 534853

$\mathrm{Fax}+48713270942$

Email jacek.szepietowski@umed.wroc.pl 
CKD-aP or "CKD-associated itch" are more suitable. ${ }^{6}$ This condition not only has a negative impact on sleep, mood, daily activities, and quality of life (QoL) but also increases the mortality risk of hemodialysis (HD) patients. $^{7,8}$ Despite this, the condition is often underestimated in clinical practice. ${ }^{9}$ Due to the etiopathogenesis of CKD-aP not being fully understood, therapy for this condition remains a challenge for dermatologists and nephrologists.

\section{Prevalence}

Over the years, studies on CKD-aP have shown variable prevalence of this condition. From the beginning of dialysis therapy, scientists reported that even $85 \%$ of the patients with ESRD may suffer from CI. ${ }^{10}$ This number decreased with the development and accessibility of renal replacement therapy. It is difficult to specify a clear cause of this phenomenon, although possible explanations could be revealed through more precisely performed dialysis based on $\mathrm{Kt} / \mathrm{V}$ or creatinine-clearance measurements.

The usage of more modern and biocompatible dialyzers can also bring about this positive effect. ${ }^{11}$ Additionally, by learning about other new factors that may cause uremic pruritus, it is possible to control them. One of the possible explanations is better control of calcium and phosphate metabolism in CKD patients. Pisoni et $\mathrm{al}^{12}$ in 2006 presented the results of the large international Dialysis Outcomes and Practice Patterns Study (DOPPS). The research assessed CI in 18,801 HD patients from 12 countries for 1996-2004. The first phase of the study focused on 1996-2001 (DOPPS I) and the second 2002-2004 (DOPPS II). Those perceiving moderateextreme itch came to $45 \%$ and $42 \%$, respectively, which confirmed a decreasing tendency of CKD-aP prevalence. A follow-up (2012-2015, DOPPS V), which involved 6,256 patients from 17 countries, showed that the proportion of patients with moderate or severe itch had declined to $37 \%{ }^{13}$ Rayner et al $^{13}$ also emphasized how strongly underestimated CKD-aP is among nephrologists. Of HD patients in their study, $17 \%$ with CI did not report their symptoms to any health-care provider and $18 \%$ were not receiving any therapy. Similar results were observed for dialysis outcomes and practice patterns in Japan, where moderate-xtreme pruritus was noted by $44 \%$ of $\mathrm{HD}$ patients between 1999 and 2004. ${ }^{14}$ A German crosssectional study investigated $860 \mathrm{HD}$ patients and revealed CI prevalence of $25 \%$ and 12-month prevalence $27.2 \%$. Approximately $35 \%$ of subjects had suffered from CI at least once in their lifetime. ${ }^{15}$ A meta-analysis of 42 crosssectional studies showed that the prevalence of CKD-aP ranged between $18 \%$ and $97.8 \%$ and the overall prevalence of CKD-aP reached 55\%. The analysis did not find any difference in prevalence the sexes. Pooled prevalence in male and female patients was $55 \%$. CI occurred comparably often in patients undergoing peritoneal dialysis (PD) and HD patients (56\% and 55\%, respectively). ${ }^{16}$ However, a South Korean study assessed pruritus in 648 patients with ESRD and showed that not only prevalence (62.5\% vs $48.3 \%$ ) but also intensity of itch measured by a visual analogue scale (VAS) was significantly higher in PD patients than HD patients. ${ }^{17}$ On the other hand, Wu et $\mathrm{al}^{18}$ showed the opposite results. VAS scores were significantly higher in HD patients than PD patients. This notwithstanding, another study showed a lack of significant difference in severity of itching and similar prevalence of $\mathrm{CI}$ in HD and PD patients (61.8\% and $61.5 \%$, respectively). ${ }^{19}$ The research also investigated pruritus in a group of patients with stage 4 or 5 CKD without dialysis therapy, where the prevalence of CI was $43.2 \%$. Another cross-sectional study determined the prevalence of CI in a group of 3,780 non-dialysis patients with CKD stages 35. The results showed that the prevalence of moderateextreme pruritus was $24 \%$ and was more likely in older patients, women, and those with stage 5 CKD, lung disease, diabetes, and physician-diagnosed depression. ${ }^{20}$ Similar prevalence was found in a cross-sectional study of 402 stage $2-5 \mathrm{CKD}$ patients. On the contrary, the prevalence of CKD-aP did not correlate with CKD stage and reached $18.9 \% .^{21}$

CI has been well investigated not only in adult populations but also among pediatric patients. CKD-aP in children occurs less commonly and with a more benign course than in adults. ${ }^{22}$ Data from German pediatric dialysis centers showed that only $9.1 \%$ of 199 children perceived itch. Reported intensity of pruritus was not severe. ${ }^{23}$ A multicenter Polish study found that pruritus affected $20.8 \%$ of children with CKD in stages $3-5 .^{24}$ This was $18.4 \%$ in a group of predialysis patients and $23.5 \%$ on dialysis (HD or PD). The severity, duration, and location of pruritus did not statistically vary by method of applied therapy.

\section{Underestimation}

Despite the prevalence of CKD-aP — approximately $40 \%$ in HD patients - the problem appears to be markedly underestimated by clinicians. In phase V of DOPPS, $65 \%$ 
of medical directors estimated that $<5 \%$ of their patients had severe pruritus, and overall they underestimated the prevalence of pruritus in $69 \%$ of facilities. Furthermore, as mentioned before, patients tend not to report CI to healthcare providers. This varied from $8 \%$ in Italy and $12 \%$ in Gulf countries to $21 \%$ in Sweden and $33 \%$ in the US. ${ }^{13}$ This may be due to patients' fear of numerous medical tests and extension of the diagnostic process, which can be burdensome for them. Years after reporting the CKD-aP and not receiving effective therapy, patients may feel resigned. A German cross-sectional survey completed by 204 nephrologists showed that most respondents estimated the prevalence of $\mathrm{CI}$ in $\mathrm{HD}$ patients to be $<30 \%$. This figure is inadequate to compare with international CKD-aP prevalence. The authors of that study presumed that clinicians neglecting this problem may be due to a lack of knowledge of effective therapy for CKD-aP. ${ }^{25}$ It is important to emphasize that lack of reporting this burdensome problem very often may be caused by a lack of interest and questions from nephrologists. A lack of available gold-standard therapy that could help patients intensifies this trend.

\section{Pathogenesis}

Scientists have developed several hypotheses regarding the development of pruritus in chronic renal failure, but the precise etiopathogenesis of this phenomenon remains elusive. False assumptions about the pathophysiological mechanisms of CKD-aP slow the discovery of better therapy in clinical practice; therefore, deeper research is necessary for breakthroughs in this area. This paper presents the most popular and proven theories as follow.

\section{Xerosis}

Characterized by rough and scaly skin, xerosis is a common complication in HD patients, with prevalence of $50 \%-85 \%$ and occurring with greater frequency in PD patients than HD patients. ${ }^{26}$ Evaluation of this skin condition among children with CKD was first performed by Wojtowicz-Prus et al. ${ }^{27}$ Approximately $68 \%$ of children undergoing dialysis presented xerosis. Based on published studies, it can be concluded that xerosis is a risk factor associated with CKD-aP. ${ }^{28,29}$ Research has shown that xerosis has an impact on the severity of itch. ${ }^{30}$ Morton et $\mathrm{al}^{31}$ demonstrated not only a correlation between itch and reduced stratum corneum hydration but also the efficacy of emollients in relieving the pruritus. However, not all studies in this area have confirmed these findings.
Yosipovitch et $\mathrm{al}^{32}$ did not find a correlation between xerosis and itch. Similarly, in another cross-sectional study, there was no significant difference in xerosis prevalence between pruritic and nonpruritic patients. ${ }^{33}$ Despite these discrepancies, regular use of emollients is widely recommended for patients with CKD-aP and may improve not only dryness of the skin but also itch severity and patients' QoL. ${ }^{34-36}$

\section{CKD-aP as an Inflammatory Disease}

Results of a multicenter study showed that inflammation and dysregulation of the immune system play a great role in the pathogenesis of CKD-aP. In research on $13 \mathrm{HD}$ patients with $\mathrm{CKD}-\mathrm{aP}$ and 13 without $\mathrm{CKD}-\mathrm{aP}$ serum levels of inflammatory markers, IL6 and C-reactive protein were significantly elevated in patients with pruritus versus those without. This may be explained by augmented $T_{h} 1$ lymphocyte differentiation in patients suffering from CKD-aP. ${ }^{36}$ Fallahzadeh et $\mathrm{al}^{37}$ supported the theory of $\mathrm{T}_{\mathrm{h}}$ 1 overactivity, showing significantly increased levels of the proinflammatory cytokine IL2 in HD patients with itch versus those without it. Two studies confirmed an important role of IL31 in CKD-aP pathophysiology, which may cause itch by stimulating peripheral nerve endings. Serum levels of IL31 were higher in patients reporting uremic itch. ${ }^{38,39}$ Despite this fact, a randomized double-blind placebo-controlled study with nemolizumab, a monoclonal antibody against IL31RA, did not find statistically significant reductions of VAS scores in CKD-aP patients. ${ }^{40}$ However, further investigation with a bigger, more representative group is required.

\section{Uremic Toxins}

CKD prevents proper elimination of various substances resulting from metabolic processes and predispose to its accumulation in the organism. These compounds, which interact negatively with various biological functions, are known as uremic toxins (UTs) and can be distinguished into three subgroups: small solutes, middle molecules, and protein-bound toxins. In 2021, the European Uremic Toxin (EUTox) database ${ }^{41}$ listed 130 substances. Low-molecular weight molecules can be readily removed during the process of dialysis. One of the substances belonging to this group - uric acid - not only has an impact on CKD progression and mortality risk but can also cause CKD$\mathrm{aP}^{42}$ According to a study performed by Wang et $\mathrm{al}^{43}$ on 320 patients with $\mathrm{CKD}$, pruritus was associated with higher levels of uric acid. However, the outcomes of two 
other studies were contrary to this. ${ }^{21,44}$ The aforementioned research also estimated the role of protein-bound UTs (PBUTs), ie, indoxyl sulfate (IS) and $p$-cresyl sulfate (PCS), in the pathogenesis of pruritus. PBUTs are predominantly excreted by renal tubular secretion, which cannot be replaced by conventional dialysis. Thereby, they are barely eliminated in patients undergoing $\mathrm{HD}$ or $\mathrm{PD}^{45}$ Patients with CKD-aP have higher total levels of IS and PCS than patients without itch. Total PCS concentration is significantly associated with pruritus severity. ${ }^{43}$ Another study investigated the effect of IS, PCS, and uremic sera from CKD patients on PAR2 expression in normal human epidermal keratinocytes. Both PBUTs and CKD induced PAR2 expression and upregulated PAR2 expression in skin samples taken from human and mouse CKD subjects compared to healthy controls. ${ }^{46}$ Similarly, Moon et $\mathrm{al}^{47}$ found significantly higher epidermal PAR2 expression in ESRD patients then in controls. In addition, a positive correlation between PAR2 expression and VAS pruritus scores was found. All these findings and the implication that PAR2 is a histamine-independent pruritic mediator confirmed the possible role of this receptor in CKD-aP etiopathogenesis. ${ }^{48} \mathrm{Wu}$ et al ${ }^{49}$ performed metabolic profiling on 200 uremic patients to find metabolites associated with CKD-aP. They found nine markers likely to play a role in the pathogenesis of CKD-aP. Metabolites associated with severe CKD-aP were LysoPE (20:3 $[5 Z, 8 Z, 11 Z] / 0: 0), p$-cresol glucuronide, LysoPC (20:2 [11Z,14Z]), hypotaurine, 4-aminohippuric acid, LysoPC (16:0), phenylacetic acid, kynurenic acid, and androstenedione. It must be noted, however, that it is difficult to draw any direct causal relationship between elevated serum levels of these compounds and CKD-aP occurrence. On the contrary, in their metabolomic analysis of plasma of HD patients with severe pruritus versus mild/no pruritus, Bolanos et $\mathrm{al}^{50}$ did not find any solutes associated with pruritus.

\section{Calcium and Phosphorus Metabolism in CKD}

CKD leads to imbalances in calcium, phosphorus, and vitamin D metabolism. An initial theory of CKD-aP mechanism also included calcium phosphate skin deposits, which arise as a result of imbalance between calcium and phosphorus in HD patients' blood and are able to activate local nerve fibers. ${ }^{51,52}$ In 1985 Blachley et al ${ }^{53}$ suggested that an increased number of divalent ions found in skin biopsies obtained from patients with CKD-aP may lead to microprecipitation of calcium or magnesium phosphate and be the cause of pruritus. Momose et $\mathrm{al}^{54}$ found higher deposition of calcium ions in the basal layer of the epidermis in patients with moderate-severe itch versus patients without. Hyperphosphatemia, hypocalcemia, and decreased calcitriol production can all increase parathyroid hormone $(\mathrm{PTH})$ production and consequently cause secondary hyperparathyroidism. ${ }^{55} \mathrm{PTH}$ has been proposed by some authors as a pruritogenic factor. This conclusion was made based on studies that confirmed reductions in CKDaP after parathyroidectomy. ${ }^{56,57}$ Makhlough et $\mathrm{al}^{58}$ found a significant difference in $\mathrm{CKD}-\mathrm{aP}$ intensity between patients with and without hyperparathyroidism (5.71 \pm 5.39 and $4.93 \pm 2.93$ points, respectively; $P=0.005$ ). PTH levels correlated with severity of pruritus in HD patients. ${ }^{58}$ However, other studies did not support the role of PTH as a mediator of CKD-aP. ${ }^{33,59,60}$ Intradermal injections of PTH analogues did not induce pruritus or any other cutaneous reaction in dialysis patients or control groups. This hormone was not detected in skin biopsies of HD patients either. ${ }^{61}$ Additionally, research performed by Duque et al ${ }^{62}$ on 105 HD patients excluded the role of PTH and serum phosphorus in presence or intensity of itch, but demonstrated a positive correlation between CKD-aP and calcium serum concentration. This interdependence was confirmed by several other studies, including DOPPS, which identified other factors associated with pruritus as well: longer period of dialysis, male sex, $\mathrm{Kt} / \mathrm{V}_{\text {urea }}$ (ratio representing fractional urea clearance) $<1.5$, and lower serum levels of albumin, ferritin, and hemoglobin. ${ }^{12,55,63}$

\section{Mast Cells}

Histamine is well known as a classical itch mediator released from mast cells. However, it plays a key role only in certain pruritic diseases, such as mastocytosis or urticaria. Initially, the significance of this potential pruritogen was thoroughly tested in terms of CKD-aP. Various studies showed a positive correlation between serum levels of histamine and CKD-aP, ${ }^{64,65}$ whereas others disproved this theory. ${ }^{66,67}$ Additionally, according to different reports, mast cells occur in increased numbers, are diffusely spread, and more often degranulated in the skin of patients suffering from CKD-aP than in healthy controls. ${ }^{68-71}$ Nonetheless, Mettang et $\mathrm{al}^{72}$ did not confirm that histamine plasma levels and number of mast cells in the skin correlated with the presence of CKD-aP. Another pruritogenic mediator released from mast cells is tryptase. 
Dugas-Breit et $\mathrm{al}^{73}$ demonstrated a significant correlation between tryptase serum levels and itch severity. Likewise, serum levels of serotonin were higher in patients with CKD-aP than the control group. ${ }^{74}$ With the therapeutic use of a $5 \mathrm{HT}_{3}$-receptor inhibitor, ondansetron, significant reduction in the severity of pruritus has been observed. ${ }^{75}$ Despite these contradictory findings, personal clinical experience affirms a lack of antihistamine effectiveness in CKD-aP therapy.

\section{Opioid System}

The opioid system is one of the several components involved in the etiopathogenesis of CKD-aP. Exogenous opioids, eg, morphine, are enabled to induce itch as a side effect. The incidence of opioid-induced pruritus depends on the route of administration and occurs in $10 \%-50 \%$ of intravenous administrations and $20 \%-100 \%$ of neuraxial administrations. ${ }^{76}$ This fact inspired scientists to examine if opioid receptors were somehow associated with chronic pruritus. Bergasa et $\mathrm{al}^{77}$ supported the hypothesis that cholestatic pruritus is modulated by endogenous opioids. They proved the effectiveness of opiate antagonists in alleviating this itch. Thus far, published reports have suggested that activation of $\mu$-opioid receptors can trigger the itch and agonists of $\kappa$-opioid receptors are able to reduce the itch by inhibiting histamine and substance $\mathrm{P}^{78,79}$ Studies utilizing mouse models have revealed that the activation of central $\kappa$-opioid receptors antagonize the central $\mu$-opioid receptor, thereby reducing itch sensation. ${ }^{80}$ Wieczorek et $\mathrm{al}^{81}$ assessed the expression of $\mu$ - and $\kappa$-opioid receptors in the skin of HD patients with and without uremic pruritus, and concluded that changes in the peripheral opioid system may play an important role in CKD-aP pathogenesis. This study demonstrated a negative correlation between skin expression of $\kappa$ opioid receptors and the intensity of CKD-aP. All these observations prompted scientists to experimentally implement opioid agonists and antagonists in the treatment of CKD-aP, which brought diverse outcomes (reviewed in subsequent sections).

\section{Neuropathy}

Dysfunction of the central or peripheral nervous system is considered another etiopathogenetic mechanism in CKDaP. Itch can be caused by centrally acting mediators, defects in the peripheral sensory pathway, cortical hypersensitivity, decreased cortical inhibitory mechanisms, or a defective spinal cord inhibition. ${ }^{35}$ A positive correlation between itch severity and occurrence of paresthesia in HD patients has been found. Most pruritic patients also develop peripheral sensorimotor neuropathy and

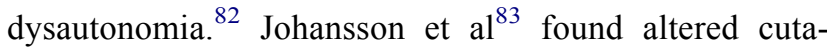
neous innervation in $12 \mathrm{CKD}$ patients in whom nerve fibers sprouted through the epidermis, in contrast to healthy controls. Another study found a reduction in total number of skin nerve terminals in uremic patients. ${ }^{84}$ Additionally, central brain neuropathy has been confirmed in functional magnetic resonance imaging of the brain in 13 patients undergoing HD and suffering from pruritus. ${ }^{85}$ Sorour et al ${ }^{86}$ aimed to evaluate serum levels of two neurotrophins - BDNF and NT4 - in 60 uremic patients with pruritus, 60 nonpruritic uremic patients, and 60 healthy subjects. The results showed not only significantly increased serum levels of NT4 in uremic patients with pruritus but also revealed a positive correlation between concentrations of NT4 and the severity of CKD-aP. Serum BDNF levels were higher in uremic patients than controls, but the presence of pruritus did not significantly influence the concentration of this neurotrophin. Natriuretic polypeptide B, also known as brain natriuretic peptide (BNP), has been described as a neuropeptide enabled to activate pruriceptive neurons in mice. ${ }^{87}$ In a cross-sectional study, serum levels of BNP were found to be frequently elevated in HD patients. As such, the authors suggested BNP as one of many possible causes of daytime CKD-aP. ${ }^{88}$

\section{Other Risk Factors of CKD-aP}

According to DOPPS, patients on HD with coexisting hepatitis $\mathrm{C}$ infection are 1.29 times more likely to perceive CKD-aP. ${ }^{12}$ This viral infection predisposes to development of CI, due to cholestasis, induction of interferonstimulated gene,s and elevated production of cytokines (eg, IL8) and chemokines (eg, CCL2, CXCL1, and CXCL5). ${ }^{22,35}$ Interestingly, hepatitis $\mathrm{B}$ does not show a significant association with pruritus, and this has raised the question of whether the pathogenesis of pruritus differs between these two diseases.de Kroes and Smeenk found elevated serum levels of vitamin A in all 35 CKD patients included in their research. However, there was no correlation between vitamin A concentration and the presence of CKD-aP. Two other studies have reported that increased serum levels of aluminum correlate significantly with the occurrence and intensity of CKD-aP. ${ }^{8922}$ 


\section{Clinical Presentation}

Clinical presentation of CKD-aP assessed in studies has varied among studied populations. In general, the sensation of the itch affects large, discontinuous regions of the skin and shows bilateral symmetry. It is very often unceasing, recurrent, and the intensity seems to be worse during the night. ${ }^{90}$ Clinically, excoriations, erosions, ulcerations, nodules, or dyspigmentation can be observed, mostly as secondary lesions caused by scratching. Certain factors are known to exacerbate or reduce itching, including heat, dialysis, stress, cold, physical activity, or showering. ${ }^{91}$ CKD-aP can be localized or generalized. Weiss at $\mathrm{al}^{92}$ observed that the most common location of CKD-aP is the legs, back, and scalp. The results were similar to a study conducted by Heisig et al. ${ }^{93}$ Overall, 38\% of respondents reported a single location of the itch mostly the back, lower extremities, scalp, upper extremities, and abdomen - and bilateral symmetry was predominant. Generalized itch presented in $26.6 \%$ of the patients. On the other hand, a cross-sectional study on Iranian HD patients showed generalized pruritus in $70 \%$ of respondents. ${ }^{33}$ Ozen et al ${ }^{94}$ estimated entire-body pruritus to be present in $35.3 \%$ of patients. Another important aspect that is constantly assessed by researchers is the intensity of CI. In a large German study, mean severity of itch measured with a VAS was $4.1 \pm 1.7$ points, while severity at the time of investigation amounted to $4.2 \pm 2.6$ points and the worst severity within the last 6 weeks was $6.5 \pm 2.5$ points. $^{92}$ Mathur et $\mathrm{al}^{90}$ showed that mean worst itching intensity for enrolled patients was $59.9 \mathrm{~mm}$ using the $100 \mathrm{~mm}$ VAS. Scores were significantly higher for the 12-hour nighttime period than for the 12-hour daytime period, which corresponds with the research on patients undergoing PD conducted by Minato et al. ${ }^{95}$ Additionally, in DOPPS, a third of patients were most bothered by itch at night. ${ }^{13}$

Apart from the time of day, there are many other factors that can affect the course of itch. A study on 130 HD patients conducted at our center revealed that the frequency of itching can positively correlate with xerosis. Itch appeared more often $(56.2 \%)$ in patients with very rough skin than patients with rough $(34.5 \%)$ or slightly dry skin (27\%). ${ }^{96}$ According to Ozen et al, ${ }^{94}$ dry skin is a risk factor of CKD-aP. In other research skin dryness just after rest was the second-most common exacerbating factor of chronic pruritus in patients undergoing dialysis. ${ }^{97}$ Heat, sweat, wool clothing, and stress were aggravating factors, while activity, sleep, hot/cold showers, and cold temperatures were considered ameliorating factors. Surprisingly, dialysis had no significant influence on itch severity. ${ }^{97}$ Other studies have revealed a connection between the dialysis process and itching. About $29 \%$ of patients in a Polish study reported itch to be the most severe during, at the end, or immediately after dialysis. ${ }^{93}$ Rayner et $\mathrm{al}^{13}$ found that $15 \%$ of the patients admitted that the worst itch was perceived during the dialysis session and $9 \%$ indicated the period soon after the session. However, for $14 \%$, the itch was the most intense on days without dialysis. Some authors have emphasized the influence of the dialysis membrane on pruritus and hypothesized that some pruritogenic cytokines or substances may be activated after blood contact with membranes. This thesis needs more precise evaluation. A positive significant correlation has been found between HD period and total pruritus score. ${ }^{96}$ Interestingly, Rad et $\mathrm{al}^{98}$ proved that the severity of pruritus was significantly reduced in patients receiving a cool dialysis solution $\left(35.5^{\circ} \mathrm{C}\right)$ during three consecutive dialysis sessions.

\section{CKD-aP Assessment}

CI should be characterized multidimensionally. Questionnaires, surveys, and similar tools are the best way to evaluate this subjective sensation. The IFSI recommends estimating not only the severity of itch but also its clinical course and consequences. ${ }^{99}$ Several scales are widely used to rate the intensity of CI. Numeric rating scales (NRSs) are the most commonly used tool for selfreported pruritus intensity. Visual analogue and verbal rating scales are equally helpful instruments. These quick and undemanding tools should be used together with at least one multidimensional questionnaire assessing frequency, duration, and distribution of the itch, as well as impact on daily activities, sleep, and psychosocial life. Such an extensive assessment of CKD-aP may be of help in evaluation of the effects of applied itch therapy and comparability of studies. ${ }^{100}$ Examples of such instruments are the 5-D Itch Scale, four-item Itch Questionnaire, Patient Benefit Index for Pruritus, Skindex 10, and Brief Itching Inventory. Due to the enormous impact of CKD-aP on QoL, assessment of this aspect in patients with CI is significant. The Dermatology Life Quality Index (DLQI) is a popular tool to evaluate QoL in patients with various dermatological diseases. However, ItchyQoL, an instrument dedicated to estimating the influence of $\mathrm{CI}$ on QoL, appears to be the best choice. Despite various instruments 
describing itch in use, only recently has a specific instrument for CKD-aP — Uremic Pruritus in Dialysis Patients - questionnaire been created. ${ }^{101}$ It evaluates three dimensions of UP in patients on dialysis: signs and symptoms, sleep, and psychosocial burden during the last 2 weeks. Besides the original version, only Chinese and Polish versions of this questionnaire have been created and validated. $^{102,103}$

\section{Clinical Outcomes}

CKD-aP not only has a negative impact on patients' QoL but also consequently leads to impairment of various patient-oriented outcomes and increased mortality risk. In the first and second part of DOPPS, ${ }^{12}$ patients suffering from moderate-extreme pruritus had 2.3-5.2 the odds of feeling drained and 1.3-1.7 times the odds of physiciandiagnosed depression than patients not affected by pruritus. uring the QoL results showed that patients strongly bothered by itchy skin had mental and physical composite scores 3.1-8.6 points lower than patients with no or mild pruritus $(P<0.0001)$. Likewise, poor sleep quality associated with waking up at night was mentioned by approximately $45 \%$ of patients with moderate-severe pruritus. In a group with mild/no pruritus, this amounted to only $29 \%$. A correlation between severity of perceptible itch and mortality risk was also found. Patients with moderateextreme pruritus had a $17 \%$ higher mortality risk than patients not bothered by pruritus. ${ }^{12}$ The Japanese DOPPS confirmed these findings: researchers found a $22 \%$ higher mortality rate for patients with moderate or extreme pruritus. This condition also induces 1.9-3.7 times the probability of impaired quality of sleep. ${ }^{14}$ Interestingly, in an Italian study, pruritus was associated with 8.4 times the adjusted odds of poor sleep. ${ }^{104}$ Mathur et $\mathrm{al}^{90}$ found that intensity of itch measured by VAS was significantly associated with lower health-related QoL in such domains as sleep, mood, and social relationships. Similarly, Szepietowski et al, ${ }^{9}$ using a short form scale (SF12) and the DLQI, concluded that not only CKD-aP but also uremic xerosis had a negative impact on patients' QoL and were unfortunately underestimated in clinical practice. Ibrahim et $\mathrm{al}^{105}$ assessed the QoL of $200 \mathrm{HD}$ patients using the WHOQOL-Bref questionnaire. QoL was impaired markedly in all four domains - physical health, psychological health, social relationships, and environmental health - in a group of patients with CI compared to a control group with no pruritus. All these papers highlight how strongly CKD-aP affects miscellaneous aspects of life and can lead to poor clinical outcomes.

\section{Treatment of CKD-aP}

The etiopathogenesis of CKD-aP is particularly complex, and numerous aspects remain to be explored and explained in more detail. As such, successful therapy for this condition often remains a demanding challenge for nephrologists or dermatologists. Considering common comorbidities in this group of patients, every single case ought to be considered individually, and applied therapy must be planned properly. The age of the patient, preexisting diseases, medications, and the quality and intensity of CI should be examined. Most of all, avoiding all exacerbating factors, such as allergenic and irritant substances, stress, hot drinks, alcohol, or hot and spicy food, is crucial. ${ }^{97}$ Fundamental antipruritic therapy must include reducing xerosis by moisturizing the skin.

\section{Topical Therapy}

Topical therapy is a treatment of first choice in numerous dermatological conditions. Emollients are capable of restoring the skin barrier and retaining water in the stratum corneum, which is crucial in reducing xerosis and thus can be of help in alleviating the itch. ${ }^{106}$ To achieve therapeutic effect, an appropriate amount of product and high frequency of application are essential. ${ }^{22}$ There are specific ingredients of emollients with proven antipruritic effects. In a randomized, multicenter study performed on 99 patients with uremic xerosis, 15\% glycerol and 10\% paraffin emulsion, high efficiency was found. ${ }^{107}$ The satisfactory treatment response concerned $73 \%$ of the patients compared with $44 \%$ of patients who responded to a comparator. By day 56 of that trial, patients reported significant relief from the itch (mean VAS score 10.66 $\pm 2.14 \mathrm{~mm}$ vs $40.64 \pm 3.36 \mathrm{~mm}$ at the beginning of the trial). At the end of the study, a significant improvement in patients' QoL, which was measured by the DLQI and SF12 questionnaire, was revealed. In other studies, the application of $10 \%$ urea plus dexpanthenol lotion or $\gamma$ linolenic acid cream turned out to be effective in alleviating CKD-aP. ${ }^{108,109}$ Topical capsaicin has also found the interest of scientists in local therapy. Studies have proved its safety and ability to reduce HD-induced pruritus. ${ }^{110-112}$ In Makhlough et al's ${ }^{112}$ study on 17 patients with CKD-aP, $0.03 \%$ capsaicin was applied for 4 weeks, while 17 patients from control study group received placebo. During the therapy, decrease in pruritus severity was 
greater in the study group than the placebo group $(P<0.001)$. However, it should be noted that in contrast to emollients, capsaicin may cause irritation of the skin. Therefore, this therapy should be used with great caution, especially in children, where emollients are considered the preferred approach in topical therapy. ${ }^{22}$ A prospective Polish study on $21 \mathrm{HD}$ patients using a topical cream containing structured physiological lipids and endogenous cannabinoids twice a day for 3 weeks was conducted. A marked reduction in itch severity was observed after the trial in $38.1 \%$ of the patients. ${ }^{113}$ This was probably related to the inhibition of mast-cell degranulation and histamine release, as well as the moisturizing effect of the preparation. Studies using calcineurin inhibitors in the treatment of CKD-aP have not shown conclusive results. According to Kuypers et al, ${ }^{114}$ treatment with $0.1 \%$ and $0.3 \%$ tacrolimus ointment for 6 weeks significantly reduced the severity of CKD-aP. This finding was confirmed by Pauli-Magnus et al. ${ }^{115}$ On the other hand, in a study carried out by Duque et al, ${ }^{116}$ these conclusions were refuted. Likewise, a larger, randomized, doubleblind, placebo-controlled study using 1\% pimecrolimus demonstrated a lack of efficacy of calcineurin inhibitors for the treatment of HD-related pruritus. ${ }^{117}$ Based on clinical experience, good tolerance of topical therapy, and rarity of adverse effects, it is recommended that it be used as a preliminary treatment, especially in patients presenting xerosis.

\section{Phototherapy}

Ultraviolet (UV) radiation is widely used in the treatment of various dermatoses. The effectiveness of phototherapy is related to a range of mechanisms, including inhibition of Langerhans cells, decreasing levels of proinflammatory cytokines, strengthening the skin barrier, increasing serum levels of 25 -hydroxyvitamin $\mathrm{D}_{3}$, or stimulating the apoptosis of mastocytes. ${ }^{22}$ The use of phototherapy in CKD-aP was first mentioned in the 1970s. Since then, numerous studies have reported beneficial effects after implementation of broadband UVB (290-320 nm wavelength) radiation. Additionally, several studies have proved the effectiveness of narrow-band UVB (NB-UVB) radiation, both in HD and PD patients with CI. ${ }^{118-121}$ However, a study comparing NB-UVB (treatment group) and longwave UVA radiation (control group) in patients with CKDaP did not show significant differences concerning pruritus intensity between these two groups. ${ }^{122}$ A systematic review on this topic defined heliotherapy as a beneficial, efficacious, efficient, safe method of CKD-aP treatment. IT emphasized also that broadband BB-UVB compared to other subtypes is the most effective phototherapy in this condition. ${ }^{123}$ NB-UVB may also be considered in children aged $>4$ years bothered by recurrent $\mathrm{CKD}$-aP thatdoes not respond to topical therapy, although there is still no literature available regarding its potential effectiveness and safety in this particular population. ${ }^{22}$ Finally, it must be noted that despite the established role of phototherapy in managing $\mathrm{CKD}-\mathrm{aP}$, this method can be troublesome, due to the limited availability and the necessity of frequent irradiation, mostly three to four times a week.

\section{Antihistamines and Mast-Cell Stabilizers}

Antihistamines are often the first-line therapy in CI, primarily when it comes to the use of over-the-counter drugs. According to DOPPS data, antihistamines were very widely prescribed for pruritus by doctors who were not skin specialists: $57 \%$ of medical directors chose oral antihistamines as an "appropriate" therapy dedicated to CKDaP. $^{13}$ This tendency is not substantiated in light of the research and expert opinions, which emphasize poor or moderate antipruritic effects of histamine-receptor antagonists in CKD-aP. ${ }^{91,124-129}$ Additionally, some reviews have suggested that the relief perceived after administration of the antihistamines may be a result of a sedative effect, rather than an antipruritic mechanism. On account of its limited value and risk of oversedation in elderly populations, this group of drugs should be avoided for this condition. ${ }^{91}$ Antihistamines are not a recommended modality in CKD-aP, and it is crucial to suppress their overuse in the subtype of CI. On the other hand, several recent studies have proved that the use of mast-cell stabilizers, which preclude histamine release, brings satisfactory effects in the treatment of CKD-aP. ${ }^{130}$ Both ketotifen and cromolyn sodium have proved to be effective in reducing itch severity. ${ }^{67,131}$ Furthermore, a trial on 60 HD patients in which cromolyn sodium cream $4 \%$ was applied twice a day for 4 weeks revealed significantly reduced pruritus severity compared to a placebo. ${ }^{132}$

\section{Antiepileptic Drugs}

Gabapentin is an anticonvulsant medication, an analogue of $\gamma$-aminobutyric acid, that is widely used in therapy for focal seizures and neuropathic pain. The mechanism of action of gabapentin in the treatment of CKD-aP is not fully known, but due to binding to $\alpha_{2} \delta$ subunits of calcium channels and suppressing the influx of calcium into nerves, 
this drug is able to discontinue itch. A systematic review of randomized controlled trials using gabapentin as a treatment for pruritus in patients undergoing HD established that gabapentin significantly alleviated CKD-aP and was a safe choice. A pooled analysis of seven studies showed reduced VAS scores among HD patients. Furthermore, side effects associated with the therapy were well tolerateds. ${ }^{133}$ Another systematic review emphasized that effectiveness of gabapentin in CKD-aP has been evidenced in the greatest number of trials compared to other interventions. ${ }^{134}$ Pregabalin, which is another antiepileptic drug with similar mechanism of action to gabapentin, is also advantageous in CKD-aP management and may be effective in patients unable to tolerate the latter. ${ }^{135}$ Ravindran et $\mathrm{al}^{136}$ concluded that pregabalin was associated with fewer side effects than gabapentin. Proven effectiveness of these two antiepileptics makes them the main choice in CKD-aP oral therapy. ${ }^{136,137}$

\section{Opioid-Receptor Agonists and Antagonists}

Difelikefalin, a highly selective peripheral agonist of the $\kappa$-opioid receptor, can be seen as a new and revolutionary treatment for pruritus in patients undergoing HD. ${ }^{138}$ It is the first and only therapy approved by the US Food and Drug Administration for treatment of moderate-severe CKD-aP in adults undergoing HD. Injections of difelikefalin are a real breakthrough in $\mathrm{CKD}-\mathrm{aP}$ treatment and should be considered as a first-line therapy. In one study, ifelikefalin $0.5,1.0$, or $1.5 \mu \mathrm{g} / \mathrm{kg}$ was administered intravenously three times a week for 8 weeks to HD patients with moderate-severe pruritus. A significant reduction from baseline in itch intensity scores at week 8 favored all difelikefalin doses combined versus placebo $(P=0.002)$. At the end of the trial, $59 \%$ of patients receiving difelikefaline reported more than 3-point improvements in mean weekly Worst Itch Intensity NRS (WI-NRS) scores compared to $29 \%$ in the placebo group. The study also demonstrated that difelikefalin improved patients' sleep, mood, and social functioning. A significantly larger reduction from baseline in mean Skindex-10 total score in a study group over the control group was observed $(-16.4$ and -8.2 , respectively; $P<0.001$ ). Sleep disturbance measured by the Medical Outcomes Study scale in all difelikefalin combined groups had decreased after 8 weeks' therapy $(P \leq 0.006){ }^{139}$ Similarly, in a double-blind, placebo-controlled, phase III trial, more patients reported at least 3 points of improvement in itch severity measured by the WI-NRS than patients without treatment $(49.1 \%$ vs $27.9 \%, P<0.001)$. The most common adverse events associated with difelikefalin were diarrhea, dizziness, and vomiting. The severity of side effects was generally mild-moderate, and they resolved without evident clinical consequence. $^{140}$

In a systematic review and meta-analysis conducted by Jaiswal et al, ${ }^{78}$ nalfurafine, a selective $\kappa$-opioid agonist, was mentioned as a potentially effective treatment for CKD-aP. Two studies showed reductions in itch severity in HD patients after 2 weeks of orally applied nalfurafine. In a study on 86 patients who received $5 \mu \mathrm{g}$ /day nalfurafine and 58 who received placebo, a 50\% decrease from initial "worst itching" score assessed by VAS was reported by $36 \%$ of patients included in therapy and by only $14 \%$ of respondents in the control group. ${ }^{141}$ Similarly, in a prospective randomized, placebo-controlled study, Kumagai et al $^{142}$ showed that decreases in VAS scores were markedly larger in a group receiving treatment than a placebo group. The most frequent adverse reaction to nalfurafine was insomnia. Four of six patients with this side effect discontinued the therapy. Wikström et al ${ }^{141}$ also mentioned headache, vertigo, nausea, and vomiting as common side effects. Both studies emphasized that adverse events were transient and easily resolved, which makes nalfurafine a safe agent for patients who are undergoing routine HD and suffering from CKD-aP. ${ }^{141,142}$ However, both studies that evaluated the effectiveness of $\kappa$-opioid agonists showed quite high percentages of placebo effectiveness. In a study evaluating difelikefalin, a placebo decreased the intensity of CKD-aP by at least 3 points in WI-NRS score in $27.9 \%$ of patients. ${ }^{140}$ Wikström et $\mathrm{al}^{141}$ found that $14 \%$ of patients in a placebo group reported a 50\% decrease from baseline in "worst itching" VAS scores. According to the authors, subjective improvement in this chronic and burdensome condition can arise from increased attention given to the patients and their confidence in receiving the right therapy. The effectiveness of the $\mu$-receptor antagonist naltrexone in CKD-aP varied between the studies. Naltrexone $50 \mathrm{mg} /$ day received orally for 7 days significantly reduced CKDaP in a group of 15 HD patients. ${ }^{143}$ Notwithstanding, Pauli-Magnus et al ${ }^{144}$ established that antipruritic therapy of CKD-aP with naltrexone was ineffective and the frequency of side effects high. Another opioid mediator applied in patients with moderate or severe CKD-aP with a satisfactory effect was nalbuphine. It is a mixed $\kappa-$ 
agonist/ $\mu$-antagonist opioid modulator. In a large, multicenter, randomized, double-blind, placebo-controlled trial, 373 HD patients received extended-release nalbuphine tablets (60 or $120 \mathrm{mg}$ ) or placebo for 8 weeks. Theere was a significant reduction in itch severity in the group receiving $120 \mathrm{mg}$ in comparison to placebo group. In contrast to placebo, this dose significantly improved sleep disturbances caused by itch. ${ }^{145}$

\section{Toxin Removal}

Several studies have examined dialysis efficiency in the context of CKD-aP. Interestingly, researchers found discrepant results concerning the relationship between $\mathrm{Kt} / \mathrm{V}$ values and the presence of itch in HD patients. Hiroshige et $\mathrm{al}^{146}$ were the first to reveal that higher dialysis efficacy leads to reductions in prevalence and intensity of pruritus in HD patients. A prospective cohort study of patients receiving maintenance $\mathrm{PD}^{147}$ found that weekly total $\mathrm{Kt} / \mathrm{V}<1.88$ was associated with higher itch intensity. Similarly Ko et al, ${ }^{148}$ found $\mathrm{Kt} / \mathrm{V} \geq 1.5$ and use of a high-flux dialyzer to be factors that may alleviate CKDaP. Not all results in this topic are equivocal. Duque et $\mathrm{al}^{62}$ pointed out that increasing the number of months on dialysis, skin dryness, and surprisingly higher $\mathrm{Kt} / \mathrm{V}$ positively correlated with the intensity of CKD-aP. Even when dialysis is properly optimized, the retention of middle molecules and PBUTs is inevitable However, the removal of IS and PCS may improve health, inhibit CKD progression, and most importantly decrease pruritus. $^{149}$

Originally used to inhibit poison absorption in the intestine, activated charcoal seems to be a promising solution in removing UTs. This alternative to conventional $\mathrm{HD}$ and hemodiafiltration was first described by Pederson et al. ${ }^{150}$ However, bigger and better-designed studies are necessary to prove this theory. This study showed that $6 \mathrm{~g}$ activated charcoal applied once a day for 8 weeks significantly reduced itching compared to placebo and an economical and safe therapy for CKD-aP. Another oral charcoal adsorbent, AST120, has induced reduction in PBUTs. Levels of IS, PCS, and phenyl sulfate were significantly reduced after 2 weeks' usage of $6 \mathrm{~g}$ per day in a study group of $20 \mathrm{HD}$ patients. ${ }^{151}$ However, this study did not assess the severity of pruritus in patients. On the other hand, cholestyramine, a synthetic resin thatprevents bile reabsorption in the gastrointestinal tract, noticeably improved pruritus in patients undergoing chronic HD. ${ }^{152}$ However, study was performed on a very small number of patients, and adverse effects of constipation and nausea were noted. Cupisti et $\mathrm{al}^{149}$ also emphasized the importance of hemoperfusion and dialysis membranes with activated carbon in itch therapy.

\section{Other Modalities}

Parathyroidectomy in patients with ESRD who develop secondary hyperparathyroidism is effective in alleviating CKD-aP. ${ }^{56,57,153}$ However, as mentioned before, not all studies have confirmed the pruritogenic nature of PTH. Additionally, hyperparathyroidism is not present in all patients with CKD-aP. Therefore, parathyroidectomy cannot be considered a form of CKD-aP therapy, except in the case of concurrent hyperparathyroidism. ${ }^{35}$ In some reports, reduction of itch prevalence after successful renal transplantation has been highlighted. ${ }^{154,155}$ The biggest published study on this topic thus far, conducted on 197 renal transplant recipients, showed that in $73.7 \%$ of patients the itch disappeared completely after transplantation, while in $23.7 \%$ itch had lower intensity and only $2.6 \%$ patients did not report any improvement. Nevertheless, $21.3 \%$ patients suffered from itch after transplantation, among which in $52.4 \%$ cases the itch appeared after renal transplantation. ${ }^{156}$ The supplementation of 3 fatty acids is not only relevant in the range of diseases coexisting with chronic renal failure but also, according to three studies, can be of help in decreasing itch in comparison to 6,9 , and placebo supplementation. ${ }^{157}$ Nonpharmacological methods taken from alternative medicine have also attracted the attention of researchers in this area. Acupuncture and acupressure have been found to be beneficial in CKD-aP, although some authors underline the high risk of bias in such studies. ${ }^{158-161}$ In addition, aromatherapy, stress-reduction techniques, psychotherapy, and physical exercises can be considered support strategies. ${ }^{162}$ It is vital to emphasize that in no way can these alternative methods be currently regarded as the basic or only antipruritic modality in the CDK-aP population.

\section{Conclusion}

CKD-aP is a pervasive but very often underestimated condition in patients undergoing HD or suffering from CKD, impairs QoL and increases the risk of mortality. Due to its complex etiopathogenesis, the choice of an 
effective therapy remains a challenge for clinicians. Future research looking for new factors responsible for CKD-aP can help in the development of novel drugs, specifically targeting particular molecules. Despite continuous research and considerable interest from scientists in understanding the full etiopathogenesis of CKD-aP, the results of many studies have been contradictory. The current situation requires continued research in this area and reevaluation of certain theories that may have a significant impact on the therapeutic management of patients with CKD-aP. Dspite many unknowns, we possess proven therapeutic methods. The proper algorithm in CKD-aP should consist of topical therapy, phototherapy, and systemic therapy. Among the latter, difelikefalin is the first and only therapy to be approved by the US Food and Drug Administration as treatment for moderate-severe CKD-aP. This may result in wide use of this substance as first-line therapy in the near future. Other group of systemic drugs with good effectiveness in this condition are gabapentinoids. Reasonable use of methods with proven effectiveness definitely contributes to improvements in patients' QoL and is crucial in this troublesome condition. It is necessary to underline the recent extensive interest in the role of UTs in CKD-aP. It is hoped that further research in this area will provide more effective and innovative management options in HD patients with CKD-aP.

\section{Author Contributions}

All authors made significant contributions to conception and study design, acquisition of data, or analysis and interpretation of data, took part in drafting, revising, and critically reviewing the article, agreed to submit to the current journal, gave final approval to the version to be published, and agree to be accountable for all aspects of the work.

\section{Disclosure}

Jacek Szepietowski reports personal fees from AbbVie, Leo Pharma, Menlo Therapeutics, Novartis, Pierre-Fabre, Sandoz Sanofi-Genzyme, Trevi, and Viofor, personal fees from AbbVie, Bauch, Eli-Lilly, Leo-Pharma, Novartis, and Sanofi-Genzyme, and personal fees from AbbVie, Amgen, Behringer Ingelheim, Galapagos, Incyte, InflaRx, JanssenCilag, Leo Pharma, Menlo Therapeutics, Merck, Novartis, Pfizer, Regeneron, Trevi, and UCB, outside the submitted work. The authors declare no other conflicts of interest in this work.

\section{References}

1. Song J, Xian D, Yang L, Xiong X, Lai R, Zhong J. Pruritus: progress toward pathogenesis and treatment. Biomed Res Int. 2018;2018:9625936. doi:10.1155/2018/9625936

2. National Kidney Foundation. K/DOQI clinical practice guidelines for chronic kidney disease: evaluation, classification, and stratification. Am J Kidney Dis. 2002;39(2 Suppl 1):S1-S266.

3. Hill NR, Fatoba ST, Oke JL, et al. Global prevalence of chronic kidney disease - a systematic review and meta-analysis. PLoS One. 2016;11(7):e0158765. doi:10.1371/journal.pone.0158765

4. Lv JC, Zhang LX. Prevalence and disease burden of chronic kidney disease. Adv Exp Med Biol. 2019;1165:3-15. doi:10.1007/978-981-13-8871-2 1

5. Robinson-Bostom L, DiGiovanna JJ. Cutaneous manifestations of end-stage renal disease. $J$ Am Acad Dermatol. 2000;43 (6):975-990. doi:10.1067/mjd.2000.110651

6. Patel TS, Freedman BI, Yosipovitch G. An update on pruritus associated with CKD. Am J Kidney Dis. 2007;50(1):11-20. doi:10.1053/j.ajkd.2007.03.010

7. Suseł J, Batycka-Baran A, Reich A, Szepietowski JC. Uraemic pruritus markedly affects the quality of life and depressive symptoms in haemodialysis patients with end-stage renal disease. Acta Derm Venereol. 2014;94(3):276-281. doi:10.2340/00015555-1749

8. Mollanazar NK, Koch SD, Yosipovitch G. Epidemiology of chronic pruritus: where have we been and where are we going? Curr Dermatol Rep. 2015;4(1):20-29. doi:10.1007/s13671-0140093-y

9. Szepietowski JC, Balaskas E, Taube KM, Taberly A, Dupuy P; Uraemic Xerosis Working Group. Quality of life in patients with uraemic xerosis and pruritus. Acta Derm Venereol. 2011;91 (3):313-317. doi:10.2340/00015555-1075

10. Mettang T. Pruritus in renal disease. In: Carstens E, Akiyama T, editors. Itch: Mechanisms and Treatment. Boca Raton (FL): CRC Press/Taylor \& Francis; 2014.

11. Urbonas A, Schwartz RA, Szepietowski JC. Uremic pruritus - an update. Am J Nephrol. 2001;21:343-350. doi:10.1159/000046272

12. Pisoni RL, Wikström B, Elder SJ, et al. Pruritus in haemodialysis patients: international results from the Dialysis Outcomes and Practice Patterns Study (DOPPS). Nephrol Dial Transplant. 2006;21(12):3495-3505. doi:10.1093/ndt/gft461

13. Rayner HC, Larkina M, Wang M, et al. International comparisons of prevalence, awareness, and treatment of pruritus in people on hemodialysis. Clin J Am Soc Nephrol. 2017;12(12):2000-2007. doi:10.2215/CJN.03280317

14. Kimata N, Fuller DS, Saito A, et al. Pruritus in hemodialysis patients: results from the Japanese Dialysis Outcomes and Practice Patterns Study (JDOPPS). Hemodial Int. 2014;18 (3):657-667. doi:10.1111/hdi.12158

15. Weisshaar E, Weiss M, Passlick-Deetjen J, Tschulena U, Maleki K, Mettang T. Laboratory and dialysis characteristics in hemodialysis patients suffering from chronic itch-results from a representative cross-sectional study. BMC Nephrol. 2015;16:184. doi:10.1186/s12882-015-0177-3

16. Hu X, Sang Y, Yang M, Chen X, Tang W. Prevalence of chronic kidney disease-associated pruritus among adult dialysis patients: a meta-analysis of cross-sectional studies. Medicine (Baltimore). 2018;97(21):e10633. doi:10.1097/MD.0000000000010633

17. Min JW, Kim SH, Kim YO, et al. Comparison of uremic pruritus between patients undergoing hemodialysis and peritoneal dialysis. Kidney Res Clin Pract. 2016;35(2):107-113. doi:10.1016/j. krcp.2016.02.002

18. Wu HY, Peng YS, Chen HY, et al. A comparison of uremic pruritus in patients receiving peritoneal dialysis and hemodialysis. Medicine (Baltimore). 2016;95(9):e2935. doi:10.1097/MD.0000000000002935 
19. Nakamoto H, Kobayashi T, Noguchi T, et al. Prevalence and severity of itching in patients with end-stage renal disease: treatment with nalfurafine hydrochloride. Blood Purif. 2019;47(suppl 2):45-49. doi:10.1159/000496637

20. Sukul N, Speyer E, Tu C, et al. Pruritus and patient reported outcomes in non-dialysis CKD. Clin J Am Soc Nephrol. 2019;14 (5):673-681. doi:10.2215/CJN.09600818

21. Solak B, Acikgoz SB, Sipahi S, Erdem T. Epidemiology and determinants of pruritus in pre-dialysis chronic kidney disease patients. Int Urol Nephrol. 2016;48(4):585-591. doi:10.1007/ s11255-015-1208-5

22. Reszke R, Kiliś-Pstrusińska K, Szepietowski JC. Chronic kidney disease-associated itch (CKD-aI) in children-a narrative review. Toxins (Basel). 2021;13(7):450. doi:10.3390/toxins13070450

23. Mettang T, Pauli-Magnus C, Alscher DM. Uraemic pruritus-new perspectives and insights from recent trials. Nephrol Dial Transplant. 2002;17(9):1558-1563. doi:10.1093/ndt/17.9.1558

24. Wojtowicz-Prus E, Kiliś-Pstrusińska K, Reich A, et al. Chronic kidney disease-associated pruritus in children. Acta Derm Venereol. 2016;96(7):938-942. doi:10.2340/00015555-2454

25. Weisshaar E, Matterne U, Mettang T. How do nephrologists in haemodialysis units consider the symptom of itch? Results of a survey in Germany. Nephrol Dial Transplant. 2009;24 (4):1328-1330. doi:10.1093/ndt/gfn769

26. Szepietowski JC, Reich A, Schwartz RA. Uraemic xerosis. Nephrol Dial Transplant. 2004;19(11):2709-2712. doi:10.1093/ ndt/gfh480

27. Wojtowicz-Prus E, Kiliś-Pstrusińska K, Reich A, et al. Disturbed skin barrier in children with chronic kidney disease. Pediatr Nephrol. 2015;30(2):333-338. doi:10.1007/s00467-014-2932-2

28. Goicoechea M, de Sequera P, Ochando A, Andrea C, Caramelo C. Uremic pruritus: an unresolved problem in hemodialysis patients. Nephron. 1999;82(1):73-74. doi:10.1159/000045371

29. Young AW Jr, Sweeney EW, David DS, et al. Dermatologic evaluation of pruritus in patients on hemodialysis. $N$ Y State J Med. 1973;73(22):2670-2674.

30. Mettang T, Kremer AE. Uremic pruritus. Kidney Int. 2015;87 (4):685-691. doi:10.1038/ki.2013.454

31. Morton CA, Lafferty M, Hau C, Henderson I, Jones M, Lowe JG. Pruritus and skin hydration during dialysis. Nephrol Dial Transplant. 1996;11(10):2031-2036. doi:10.1093/oxfordjournals.ndt.a027092

32. Yosipovitch G, Duque MI, Patel TS, et al. Skin barrier structure and function and their relationship to pruritus in end-stage renal disease. Nephrol Dial Transplant. 2007;22(11):3268-3272. doi:10.1093/ndt/gfm375

33. Akhyani M, Ganji MR, Samadi N, Khamesan B, Daneshpazhooh M. Pruritus in hemodialysis patients. $B M C$ Dermatol. 2005;5:7. doi:10.1186/1471-5945-5-7

34. Okada K, Matsumoto K. Effect of skin care with an emollient containing a high water content on mild uremic pruritus. Ther Apher Dial. 2004;8(5):419-422. doi:10.1111/j.1526-0968.2004.00175.x

35. Agarwal P, Garg V, Karagaiah P, Szepietowski JC, Grabbe S, Goldust M. Chronic kidney disease-associated pruritus. Toxins. 2021;13(8):527. doi:10.3390/toxins13080527

36. Kimmel M, Alscher DM, Dunst $R$, et al. The role of micro-inflammation in the pathogenesis of uraemic pruritus in haemodialysis patients. Nephrol Dial Transplant. 2006;21 (3):749-755. doi:10.1093/ndt/gfi204

37. Fallahzadeh MK, Roozbeh J, Geramizadeh B, Namazi MR. Interleukin-2 serum levels are elevated in patients with uremic pruritus: a novel finding with practical implications. Nephrol Dial Transplant. 2011;26(10):3338-3344. doi:10.1093/ndt/gfr053

38. Ko MJ, Peng YS, Chen HY, et al. Interleukin-31 is associated with uremic pruritus in patients receiving hemodialysis. $\mathrm{J} \mathrm{Am}$ Acad Dermatol. 2014;71(6):1151-1159.e1. doi:10.1016/j. jaad.2014.08.004
39. Oweis AO, Al-Qarqaz F, Bodoor K, et al. Elevated interleukin 31 serum levels in hemodialysis patients are associated with uremic pruritus. Cytokine. 2021;138:155369. doi:10.1016/j.cyto.2020.15 5369

40. Kinugasa E, Igawa K, Shimada H, et al. Anti-pruritic effect of nemolizumab in hemodialysis patients with uremic pruritus: a Phase II, randomized, double-blind, placebo-controlled clinical study. Clin Exp Nephrol. 2021;25(8):875-884. doi:10.1007/ s10157-021-02047-2

41. The European Uremic Toxins (EUTox) Database. Available from: https://database.uremic-toxins.org/home.php. Accessed May 27, 2021.

42. Oh TR, Choi HS, Kim CS, et al. Hyperuricemia has increased the risk of progression of chronic kidney disease: propensity score matching analysis from the KNOW-CKD study. Sci Rep. 2019;9 (1):6681. doi:10.1038/s41598-019-43241-3

43. Wang CP, Lu YC, Tsai IT, et al. Increased levels of total p-Cresylsulfate are associated with pruritus in patients with chronic kidney disease. Dermatology. 2016;232(3):363-370. doi:10.1159/000445429

44. Noh SH, Park K, Kim EJ. The incidence of pruritus and biochemical marker associated with pruritus in hemodialysis patients. Ann Dermatol. 2018;30(4):473-475. doi:10.5021/ad.2018.30.4.473

45. van Gelder MK, Middel IR, Vernooij RWM, et al. Protein-bound uremic toxins in hemodialysis patients relate to residual kidney function, are not influenced by convective transport, and do not relate to outcome. Toxins (Basel). 2020;12(4):234. doi:10.3390/ toxins 12040234

46. Kim SJ, Zhang X, Cho SB, Kim CH, Park HC, Moon SJ. Uremic solutes of indoxyl sulfate and $p$-cresol enhance protease-activated receptor-2 expression in vitro and in vivo in keratinocytes. Hum Exp Toxicol. 2021;40(1):113-123. doi:10.1177/0960327120945758

47. Moon SJ, Kim HJ, Cho SB, et al. Epidermal proteinase-activated receptor-2 expression is increased in end-stage renal disease patients with pruritus: a pilot Study. Electrolyte Blood Press. 2014;12(2):74-79. doi:10.5049/EBP.2014.12.2.74

48. Steinhoff M, Neisius U, Ikoma A, et al. Proteinase-activated receptor-2 mediates itch: a novel pathway for pruritus in human skin. $J$ Neurosci. 2003;23(15):6176-6180. doi:10.1523/ JNEUROSCI.23-15-06176.2003

49. Wu Q, Zhang H, Ding JR, et al. UPLC-QTOF MS-based serum metabolomic profiling analysis reveals the molecular perturbations underlying uremic pruritus. Biomed Res Int. 2018;2018:4351674. doi:10.1155/2018/4351674

50. Bolanos CG, Pham NM, Mair RD, Meyer TW, Sirich TL. Metabolomic analysis of uremic pruritus in patients on hemodialysis. PLoS One. 2021;16(2):e0246765. doi:10.1371/journal.pone.0246765

51. Verduzco HA, Shirazian S. CKD-associated pruritus: new insights into diagnosis, pathogenesis, and management. Kidney Int Rep. 2020;5(9):1387-1402. doi:10.1016/j.ekir.2020.04.027

52. Swarna SS, Aziz K, Zubair T, Qadir N, Khan M. Pruritus associated with chronic kidney disease: a comprehensive literature review. Cureus. 2019;11(7):e5256. doi:10.7759/cureus.5256

53. Blachley JD, Blankenship DM, Menter A, Parker TF 3rd, Knochel JP. Uremic pruritus: skin divalent ion content and response to ultraviolet phototherapy. Am J Kidney Dis. 1985;5 (5):237-241. doi:10.1016/s0272-6386(85)80115-3

54. Momose A, Kudo S, Sato M, et al. Calcium ions are abnormally distributed in the skin of haemodialysis patients with uraemic pruritus. Nephrol Dial Transplant. 2004;19(8):2061-2066. doi: $10.1093 / \mathrm{ndt} / \mathrm{gfh} 287$

55. Tajbakhsh R, Joshaghani HR, Bayzayi F, Haddad M, Qorbani M. Association between pruritus and serum concentrations of parathormone, calcium and phosphorus in hemodialysis patients. Saudi J Kidney Dis Transpl. 2013;24(4):702-706. doi:10.4103/ 1319-2442.113858 
56. Massry SG, Popovtzer MM, Coburn JW, Makoff DL, Maxwell MH, Kleeman CR. Intractable pruritus as a manifestation of secondary hyperparathyroidism in uremia: disappearance of itching after subtotal parathyroidectomy. $N$ Engl $J$ Med. 1968;279(13):697-700. doi:10.1056/NEJM196809262791308

57. Hampers CL, Katz AI, Wilson RE, Merrill JP. Disappearance of "uremic" itching after subtotal parathyroidectomy. $N$ Engl J Med. 1968;279(13):695-697. doi:10.1056/NEJM196809262791307

58. Makhlough A, Emadi N, Sedighi O, Khademloo M, Bicmohamadi AR. Relationship between serum intact parathyroid hormone and pruritus in hemodialysis patients. Iran J Kidney Dis. 2013;7(1):42-46.

59. Ostlere LS, Taylor C, Baillod R, Wright S. Relationship between pruritus, transepidermal water loss, and biochemical markers of renal itch in haemodialysis patients. Nephrol Dial Transplant. 1994;9(9):1302-1304.

60. Cho YL, Liu HN, Huang TP, Tarng DC. Uremic pruritus: roles of parathyroid hormone and substance P. J Am Acad Dermatol. 1997;36(4):538-543. doi:10.1016/s0190-9622(97)70240-8

61. Ståhle-Bäckdahl M, Hägermark $\mathrm{O}$, Lins LE, Törring $\mathrm{O}$, Hilliges M, Johansson O. Experimental and immunohistochemical studies on the possible role of parathyroid hormone in uraemic pruritus. J Intern Med. 1989;225(6):411-415. doi:10.1111/ j.1365-2796.1989.tb00104.x

62. Duque MI, Thevarajah S, Chan YH, Tuttle AB, Freedman BI, Yosipovitch G. Uremic pruritus is associated with higher kt/V and serum calcium concentration. Clin Nephrol. 2006;66(3):184-191. doi: 10.5414/cnp6618460

63. Hu T, Wang B, Liao X, Wang S. Clinical features and risk factors of pruritus in patients with chronic renal failure. Exp Ther Med. 2019;18(2):964-971. doi:10.3892/etm.2019.7588

64. Stockenhuber F, Kurz RW, Sertl K, Grimm G, Balcke P. Increased plasma histamine levels in uraemic pruritus. Clin Sci (Lond) 1990;79(5):477-482. doi:10.1042/cs0790477

65. Gill DS, Fonseca VA, Barradas MA, Balliod R, Moorhead JF, Dandona P. Plasma histamine in patients with chronic renal failure and nephrotic syndrome. J Clin Pathol. 1991;44(3):243-245. doi: $10.1136 /$ jcp.44.3.243

66. De Filippi C, Regazzini R, Piazza V, et al. Uraemic pruritus is not related to plasma histamine concentrations. Clin Exp Dermatol. 1995;20(4):294-296. doi:10.1111/j.1365-2230.1995.tb01328.x

67. Francos GC, Kauh YC, Gittlen SD, et al. Elevated plasma histamine in chronic uremia. Effects of ketotifen on pruritus. Int $J$ Dermatol. 1991;30(12):884-889. doi:10.1111/j.1365-4362.1991.tb04360.x

68. Szepietowski J, Thepen T, van Vloten WA, Szepietowski T, Bihari IC. Pruritus and mast cell proliferation in the skin of haemodialysis patients. Inflamm Res. 1995;44(Suppl 1):S84S85. doi:10.1007/BF01674408

69. Leong SO, Tan CC, Lye WC, Lee EJ, Chan HL. Dermal mast cell density and pruritus in end-stage renal failure. Ann Acad Med Singap. 1994;23(3):327-329.

70. Dimković N, Djukanović L, Radmilović A, Bojić P, Juloski T. Uremic pruritus and skin mast cells. Nephron. 1992;61(1):5-9. doi:10.1159/000186826

71. Matsumoto M, Ichimaru K, Horie A. Pruritus and mast cell proliferation of the skin in end stage renal failure. Clin Nephrol. 1985;23(6):285-288.

72. Mettang T, Fritz P, Weber J, Machleidt C, Hübel E, Kuhlmann U. Uremic pruritus in patients on hemodialysis or continuous ambulatory peritoneal dialysis (CAPD). The role of plasma histamine and skin mast cells. Clin Nephrol. 1990;34(3):136-141.

73. Dugas-Breit S, Schöpf $P$, Dugas $M$, Schiffl $H$, Ruëff $F$, Przybilla B. Baseline serum levels of mast cell tryptase are raised in hemodialysis patients and associated with severity of pruritus. J Dtsch Dermatol Ges. 2005;3(5):343-347. doi:10.1111/j.16100387.2005.05706.x
74. Kerr PG, Argiles A, Mion C. Whole blood serotonin levels are markedly elevated in patients on dialytic therapy. Am J Nephrol. 1992;12(1-2):14-18. doi:10.1159/000168411

75. Balaskas EV, Bamihas GI, Karamouzis M, Voyiatzis G, Tourkantonis A. Histamine and serotonin in uremic pruritus: effect of ondansetron in CAPD-pruritic patients. Nephron. 1998;78(4):395-402. doi:10.1159/000044967

76. Kumar K, Singh SI. Neuraxial opioid-induced pruritus: an update. $J$ Anaesthesiol Clin Pharmacol. 2013;29(3):303-307. doi:10.4103/0970-9185.117045

77. Bergasa NV, Alling DW, Talbot TL, et al. Effects of naloxone infusions in patients with the pruritus of cholestasis. A double-blind, randomized, controlled trial. Ann Intern Med. 1995;123(3):161-167. doi:10.7326/0003-4819-123-3-199508010-00001

78. Jaiswal D, Uzans D, Hayden J, Kiberd BA, Tennankore KK Targeting the opioid pathway for uremic pruritus: a systematic review and meta-analysis. Can $J$ Kidney Health Dis. 2016;3:2054358116675345. doi:10.1177/2054358116675345

79. Manenti L, Tansinda P, Vaglio A. Uraemic pruritus: clinical characteristics, pathophysiology and treatment. Drugs. 2009;69 (3):251-263. doi:10.2165/00003495-200969030-00002

80. Umeuchi $\mathrm{H}$, Togashi $\mathrm{Y}$, Honda $\mathrm{T}$, et al. Involvement of central mu-opioid system in the scratching behavior in mice, and the suppression of it by the activation of kappa-opioid system. Eur J Pharmacol. 2003;477(1):29-35. doi:10.1016/j.ejphar.2003.08.007

81. Wieczorek A, Krajewski P, Kozioł-Gałczyńska M, Szepietowski JC. Opioid receptors expression in the skin of haemodialysis patients suffering from uraemic pruritus. $J$ Eur Acad Dermatol Venereol. 2020;34(10):2368-2372. doi:10.1111/ jdv. 16360

82. Zakrzewska-Pniewska B, Jedras M. Is pruritus in chronic uremic patients related to peripheral somatic and autonomic neuropathy? Study by R-R interval variation test (RRIV) and by sympathetic skin response (SSR). Neurophysiol Clin. 2001;31(3):181-193. doi:10.1016/s0987-7053(01)00257-x

83. Johansson $\mathrm{O}$, Hilliges $\mathrm{M}$, Ståhle-Bäckdahl $\mathrm{M}$. Intraepidermal neuron-specific enolase (NSE)-immunoreactive nerve fibres: evidence for sprouting in uremic patients on maintenance hemodialysis. Neurosci Lett. 1989;99(3):281-286. doi:10.1016/ 0304-3940(89)90460-6

84. Fantini F, Baraldi A, Sevignani C, Spattini A, Pincelli C, Giannetti A. Cutaneous innervation in chronic renal failure patients. An immunohistochemical study. Acta Derm Venereol. 1992;72(2):102-105. doi:10.2340/0001555572102105

85. Papoiu AD, Emerson NM, Patel TS, et al. Voxel-based morphometry and arterial spin labeling fMRI reveal neuropathic and neuroplastic features of brain processing of itch in end-stage renal disease. $J$ Neurophysiol. 2014;112(7):1729-1738. doi:10.1152/jn.00827.2013

86. Sorour NE, Elesawy FM, Tabl HA, Ibrahim ME, Akl EM. Evaluation of serum levels of neurotrophin 4 and brain-derived nerve growth factor in uremic pruritus patients. Clin Cosmet Investig Dermatol. 2019;12:109-114. doi:10.2147/CCID. S190917

87. Mishra SK, Hoon MA. The cells and circuitry for itch responses in mice. Science. 2013;340(6135):968-971. doi:10.1126/ science. 1233765

88. Shimizu Y, Sonoda A, Nogi C, et al. B-type (brain) natriuretic peptide and pruritus in hemodialysis patients. Int $J$ Nephrol Renovasc Dis. 2014;7:329-335. doi:10.2147/IJNRD.S65929

89. de Kroes S, Smeenk G. Serum vitamin A levels and pruritus in patients on hemodialysis. Dermatologica. 1983;166(4):199-202. doi:10.1159/000249867

90. Mathur VS, Lindberg J, Germain M, et al. A longitudinal study of uremic pruritus in hemodialysis patients. Clin J Am Soc Nephrol. 2010;5(8):1410-1419. doi:10.2215/CJN.00100110 
91. Combs SA, Teixeira JP, Germain MJ. Pruritus in kidney disease. Semin Nephrol. 2015;35(4):383-391. doi:10.1016/j.semnephr ol.2015.06.009

92. Weiss M, Mettang T, Tschulena U, Passlick-Deetjen J, Weisshaar E. Prevalence of chronic itch and associated factors in haemodialysis patients: a representative cross-sectional study. Acta Derm Venereol. 2015;95(7):816-821. doi:10.2340/ 00015555-2087

93. Heisig M, Reich A, Szepietowski JC. Is uremic pruritus still an important clinical problem in maintenance hemodialysis patients? $J$ Eur Acad Dermatol Venereol. 2016;30(12):e198-e199. doi:10.1111/jdv.13524

94. Ozen N, Cinar FI, Askin D, Mut D. Uremic pruritus and associated factors in hemodialysis patients: a multi-center study. Kidney Res Clin Pract. 2018;37(2):138-147. doi:10.23876/j. krcp.2018.37.2.138

95. Minato S, Hirai K, Morino J, et al. Factors associated with uremic pruritus in patients undergoing peritoneal dialysis. Int J Nephrol Renovasc Dis. 2020;13:1-9. doi:10.2147/IJNRD.S224871

96. Szepietowski JC, Sikora M, Kusztal M, Salomon J, Magott M, Szepietowski T. Uremic pruritus: a clinical study of maintenance hemodialysis patients. $J$ Dermatol. 2002;29(10):621-627. doi:10.1111/j.1346-8138.2002.tb00191.x

97. Zucker I, Yosipovitch G, David M, Gafter U, Boner G. Prevalence and characterization of uremic pruritus in patients undergoing hemodialysis: uremic pruritus is still a major problem for patients with end-stage renal disease. $J$ Am Acad Dermatol. 2003;49(5):842-846. doi:10.1016/s0190-9622(03)02478-2

98. Rad M, Jaghouri E, Sharifipour F, Rakhshani M. The effects of cool dialysate on pruritus status during hemodialysis of patients with chronic renal failure: a controlled randomized clinical trial. Iran Red Crescent Med J. 2017;19(1). Available from: https:// www.sid.ir/en/journal/ViewPaper.aspx?id=520984

99. Ständer S, Augustin M, Reich A, et al. Pruritus assessment in clinical trials: consensus recommendations from the International Forum for the Study of Itch (IFSI) Special Interest Group Scoring Itch in Clinical Trials. Acta Derm Venereol. 2013;93(5):509-514. doi:10.2340/00015555-1620

100. Phan NQ, Blome C, Fritz F, et al. Assessment of pruritus intensity: prospective study on validity and reliability of the visual analogue scale, numerical rating scale and verbal rating scale in 471 patients with chronic pruritus. Acta Derm Venereol. 2012;92 (5):502-507. doi:10.2340/00015555-1246

101. Nochaiwong S, Ruengorn C, Awiphan R, et al. Development of a multidimensional assessment tool for uraemic pruritus: Uraemic Pruritus in Dialysis Patients (UP-Dial). Br J Dermatol. 2017;176 (6):1516-1524. doi:10.1111/bjd.15268

102. Li J, Chen FL, Zhao XR, et al. The reliability and validity of the 14-item uremic pruritus in dialysis patients scale (Chinese version scale). Chin J Blood Purif. 2019;18:575-578.

103. Świerczyńska K, Krajewski P, Reszke R, et al. Uraemic Pruritus in Dialysis Patient (UP-Dial) questionnaire: creation and validation of the Polish language version. Adv Dermatol Allergol. 2021. doi:10.5114/ada.2021.107271.

104. Tessari G, Dalle Vedove C, Loschiavo C, et al. The impact of pruritus on the quality of life of patients undergoing dialysis: a single centre cohort study. J Nephrol. 2009;22(2):241-248.

105. Ibrahim MK, Elshahid AR, El Baz TZ, Elazab RM, Elhoseiny SA, Elsaie ML. Impact of uraemic pruritus on quality of life among end stage renal disease patients on dialysis. J Clin Diagn Res. 2016;10(3):WC01-WC5. doi:10.7860/JCDR/2016/ 16273.7488

106. Moncrieff G, Cork M, Lawton S, Kokiet S, Daly C, Clark C. Use of emollients in dry-skin conditions: consensus statement. Clin Exp Dermatol. 2013;38(3):231-238. doi:10.1111/ced.12104
107. Balaskas E, Szepietowski JC, Bessis D, et al. Randomized, double-blind study with glycerol and paraffin in uremic xerosis. Clin J Am Soc Nephrol. 2011;6(4):748-752. doi:10.2215/ CJN.05490610

108. Chen YC, Chiu WT, Wu MS. Therapeutic effect of topical gamma-linolenic acid on refractory uremic pruritus. Am J Kidney Dis. 2006;48(1):69-76. doi:10.1053/j.ajkd.2006.03.082

109. Castello M, Milani M. Efficacy of topical hydrating and emollient lotion containing $10 \%$ urea ISDIN $^{\circledR}$ plus dexpanthenol (Ureadin $\mathrm{Rx} 10)$ in the treatment of skin xerosis and pruritus in hemodialyzed patients: an open prospective pilot trial. G Ital Dermatol Venereol. 2011;146(5):321-325.

110. Breneman DL, Cardone JS, Blumsack RF, Lather RM, Searle EA, Pollack VE. Topical capsaicin for treatment of hemodialysis-related pruritus. J Am Acad Dermatol. 1992;26 (1):91-94. doi:10.1016/0190-9622(92)70013-6

111. Tarng DC, Cho YL, Liu HN, Huang TP. Hemodialysis-related pruritus: a double-blind, placebo-controlled, crossover study of capsaicin $\quad 0.025 \%$ cream. Nephron. 1996;72(4):617-622. doi:10.1159/000188949

112. Makhlough A, Ala S, Haj-Heydari Z, Kashi Z, Bari A. Topical capsaicin therapy for uremic pruritus in patients on hemodialysis. Iran J Kidney Dis. 2010;4(2):137-140.

113. Szepietowski JC, Reich A, Szepietowski T. Emollients with endocannabinoids in the treatment of uremic pruritus: discussion of the therapeutic options. Ther Apher Dial. 2005;9(3):277-279. doi:10.1111/j.1774-9987.2005.00271.x

114. Kuypers DR, Claes K, Evenepoel P, Maes B, Vanrenterghem Y. A prospective proof of concept study of the efficacy of tacrolimus ointment on uraemic pruritus (UP) in patients on chronic dialysis therapy. Nephrol Dial Transplant. 2004;19(7):1895-1901. doi: $10.1093 / \mathrm{ndt} / \mathrm{gfh} 202$

115. Pauli-Magnus C, Klumpp S, Alscher DM, Kuhlmann U, Mettang T. Short-term efficacy of tacrolimus ointment in severe uremic pruritus. Perit Dial Int. 2000;20(6):802-803. doi:10.1177/ 089686080002000641

116. Duque MI, Yosipovitch G, Fleischer AB Jr, Willard J, Freedman BI. Lack of efficacy of tacrolimus ointment $0.1 \%$ for treatment of hemodialysis-related pruritus: a randomized, double-blind, vehicle-controlled study. $J$ Am Acad Dermatol. 2005;52(3 Pt 1):519-521. doi:10.1016/j.jaad.2004.08.050

117. Ghorbani AR, Feily A, Khalili A, Dormanesh B. Lack of efficacy of topical calcineurin inhibitor pimecrolimus $1 \%$ on pruritus of severely uremic patients: a randomized double-blind study in 60 patients. Dermatitis. 2011;22(3):167-168. doi:10.2310/6620.20 11.10110

118. Ada S, Seçkin D, Budakoğlu I, Ozdemir FN. Treatment of uremic pruritus with narrowband ultraviolet B phototherapy: an open pilot study. $J$ Am Acad Dermatol. 2005;53(1):149-151. doi:10.1016/j.jaad.2004.12.052

119. Wang TJ, Lan LC, Lu CS, et al. Efficacy of narrowband ultraviolet phototherapy on renal pruritus. J Clin Nurs. 2014;23(1112):1593-1602. doi:10.1111/jocn. 12252

120. Sherjeena PB, Binitha MP, Rajan U, et al. A controlled trial of narrowband ultraviolet B phototherapy for the treatment of uremic pruritus. Indian J Dermatol Venereol Leprol. 2017;83 (2):247-249. doi:10.4103/0378-6323.198464

121. Sapam R, Waikhom R. Role of narrow band ultra violet radiation as an add-on therapy in peritoneal dialysis patients with refractory uremic pruritus. World J Nephrol. 2018;7(4):84-89. doi:10.5527/ wjn.v7.i4.84

122. Ko MJ, Yang JY, Wu HY, et al. Narrowband ultraviolet B phototherapy for patients with refractory uraemic pruritus: a randomized controlled trial. $B r \quad J$ Dermatol. 2011;165 (3):633-639. doi:10.1111/j.1365-2133.2011.10448.x 
123. Thakur A, Chaudhari S, Chaudhari P, Thakur M. Phototherapy as a treatment for Uremic Pruritus-A review. Gen Med. 2015;3:202.

124. Schwartz IF, Iaina A. Uraemic pruritus. Nephrol Dial Transplant. 1999;14(4):834-839. doi:10.1093/ndt/14.4.834

125. Lugon JR. Uremic pruritus: a review. Hemodial Int. 2005;9 (2):180-188. doi:10.1111/j.1492-7535.2005.01130.x

126. Weisshaar E, Dunker N, Röhl FW, Gollnick H. Antipruritic effects of two different 5-HT3 receptor antagonists and an antihistamine in haemodialysis patients. Exp Dermatol. 2004;13 (5):298-304. doi:10.1111/j.0906-6705.2004.00184.x

127. Gilchrest BA, Stern RS, Steinman TI, Brown RS, Arndt KA, Anderson WW. Clinical features of pruritus among patients undergoing maintenance hemodialysis. Arch Dermatol. 1982;118 (3):154-156. doi:10.1001/archderm.1982.01650150016012

128. Berger TG, Steinhoff M. Pruritus and renal failure. Semin Cutan Med Surg. 2011;30(2):99-100. doi:10.1016/j.sder.2011.04.005

129. Russo GE, Spaziani M, Guidotti C, et al. Pruritus in chronic uremic patients in periodic hemodialysis. Treatment with terfenadine (an antagonist of histamine H1 receptors) (article in Italian). Minerva Urol Nefrol. 1986;38(4):443-447.

130. Shirazian S, Aina O, Park Y, et al. Chronic kidney disease-associated pruritus: impact on quality of life and current management challenges. Int $J$ Nephrol Renovasc Dis. 2017;10:11-26. doi:10.2147/IJNRD.S108045

131. Amirkhanlou S, Rashedi A, Taherian J, Hafezi AA, Parsaei S. Comparison of gabapentin and ketotifen in treatment of uremic pruritus in hemodialysis patients. Pak J Med Sci. 2016;32 (1):22-26. doi:10.12669/pjms.321.8547

132. Feily A, Dormanesh B, Ghorbani AR, et al. Efficacy of topical cromolyn sodium $4 \%$ on pruritus in uremic nephrogenic patients: a randomized double-blind study in 60 patients. Int $J$ Clin Pharmacol Ther. 2012;50(7):510-513. doi:10.5414/cp201629

133. Eusebio-Alpapara KMV, Castillo RL, Dofitas BL. Gabapentin for uremic pruritus: a systematic review of randomized controlled trials. Int J Dermatol. 2020;59(4):412-422. doi:10.1111/ijd.14708

134. Simonsen E, Komenda P, Lerner B, et al. Treatment of uremic pruritus: a systematic review. Am J Kidney Dis. 2017;70 (5):638-655. doi:10.1053/j.ajkd.2017.05.018

135. Rayner H, Baharani J, Smith S, Suresh V, Dasgupta I. Uraemic pruritus: relief of itching by gabapentin and pregabalin. Nephron Clin Pract. 2012;122(3-4):75-79. doi:10.1159/000349943

136. Ravindran A, Kunnath RP, Sunny A, Vimal B. Comparison of safety and efficacy of pregabalin versus gabapentin for the treatment of uremic pruritus in patients with chronic kidney disease on maintenance haemodialysis. Indian J Palliat Care. 2020;26 (3):281-286. doi:10.4103/IJPC.IJPC 21219

137. Solak Y, Biyik Z, Atalay H, et al. Pregabalin versus gabapentin in the treatment of neuropathic pruritus in maintenance haemodialysis patients: a prospective, crossover study. Nephrology (Carlton). 2012;17(8):710-717. doi:10.1111/j.1440-1797.2012.01655.x

138. Weisshaar E, Ofenloch RF. One step closer to alleviating uraemic pruritus. Nat Rev Nephrol. 2020;16(4):189-190. doi:10.1038/ s41581-020-0251-3

139. Fishbane S, Mathur V, Germain MJ, et al. Randomized controlled trial of difelikefalin for chronic pruritus in hemodialysis patients. Kidney Int Rep. 2020;5(5):600-610. doi:10.1016/j.ekir.2020.01.006

140. Fishbane S, Jamal A, Munera C, Wen W, Menzaghi F; KALM-1 Trial Investigators. A Phase 3 trial of difelikefalin in hemodialysis patients with pruritus. $N$ Engl J Med. 2020;382(3):222-232. doi:10.1056/NEJMoa1912770

141. Wikström B, Gellert R, Ladefoged SD, et al. Kappa-opioid system in uremic pruritus: multicenter, randomized, double-blind, placebo-controlled clinical studies. J Am Soc Nephrol. 2005;16 (12):3742-3747. doi:10.1681/ASN.2005020152
142. Kumagai H, Ebata T, Takamori K, Muramatsu T, Nakamoto H, Suzuki H. Effect of a novel kappa-receptor agonist, nalfurafine hydrochloride, on severe itch in 337 haemodialysis patients: a Phase III, randomized, double-blind, placebo-controlled study. Nephrol Dial Transplant. 2010;25(4):1251-1257. doi:10.1093/ ndt/gfp588

143. Peer G, Kivity S, Agami O, et al. Randomised crossover trial of naltrexone in uraemic pruritus. Lancet. 1996;348 (9041):1552-1554. doi:10.1016/s0140-6736(96)04176-1

144. Pauli-Magnus C, Mikus G, Alscher DM, et al. Naltrexone does not relieve uremic pruritus: results of a randomized, double-blind, placebo-controlled crossover study. J Am Soc Nephrol. 2000;11 (3):514-519. doi:10.1681/ASN.V113514

145. Mathur VS, Kumar J, Crawford PW, Hait H, Sciascia T; TR02 Study Investigators. A multicenter, randomized, double-blind, placebo-controlled trial of nalbuphine ER tablets for uremic pruritus. Am J Nephrol. 2017;46(6):450-458. doi:10.1159/000484573

146. Hiroshige K, Kabashima N, Takasugi M, Kuroiwa A. Optimal dialysis improves uremic pruritus. Am J Kidney Dis. 1995;25 (3):413-419. doi:10.1016/0272-6386(95)90102-7

147. Wu HY, Huang JW, Tsai WC, et al. Prognostic importance and determinants of uremic pruritus in patients receiving peritoneal dialysis: a prospective cohort study. PLoS One. 2018;13(9): e0203474. doi:10.1371/journal.pone.0203474

148. Ko MJ, Wu HY, Chen HY, et al. Uremic pruritus, dialysis adequacy, and metabolic profiles in hemodialysis patients: a prospective 5-year cohort study. PLoS One. 2013;8(8):e71404. doi:10.1371/journal.pone.0071404

149. Cupisti A, Piccoli GB, Gallieni M. Charcoal for the management of pruritus and uremic toxins in patients with chronic kidney disease. Curr Opin Nephrol Hypertens. 2020;29(1):71-79. doi:10.1097/MNH.0000000000000567

150. Pederson JA, Matter BJ, Czerwinski AW, Llach F. Relief of idiopathic generalized pruritus in dialysis patients treated with activated oral charcoal. Ann Intern Med. 1980;93(3):446-448. doi:10.7326/0003-4819-93-3-446

151. Yamamoto S, Kazama JJ, Omori K, et al. Continuous reduction of protein-bound uraemic toxins with improved oxidative stress by using the oral charcoal adsorbent AST-120 in haemodialysis patients. Sci Rep. 2015;5:14381. doi:10.1038/srep14381

152. Lu PH, Tai YC, Yu MC, Lin IH, Kuo KL. Western and complementary alternative medicine treatment of uremic pruritus: a literature review. Tzu Chi Med J. 2021;33:350. doi:10.4103/ tcmj.tcmj_151_20

153. Chou FF, Ho JC, Huang SC, Sheen-Chen SM. A study on pruritus after parathyroidectomy for secondary hyperparathyroidism. $\mathrm{J} \mathrm{Am}$ Coll Surg. 2000;190(1):65-70. doi:10.1016/s1072-7515(99)00212-4

154. Panuccio V, Tripepi R, Bellantoni M, et al. Pruritus and quality of life in renal transplant patients. Clin Transplant. 2017;31(3): e12893. doi: $10.1111 /$ ctr. 12893

155. Schricker S, Weisshaar E, Kupfer J, Mettang T. Prevalence of pruritus in a single cohort of long-term kidney transplant recipients. Acta Derm Venereol. 2020;100(4):adv00066. doi:10.2340/00015555-3421

156. Krajewski PK, Olczyk P, Krajewska M, Krajewski W, Szepietowski JC. Clinical characteristics of Itch in renal transplant recipients. Front Med (Lausanne). 2021;7:615334. doi:10.3389/fmed.2020.615334

157. Panahi Y, Dashti-Khavidaki S, Farnood F, Noshad H, Lotfi M, Gharekhani A. Therapeutic effects of omega-3 fatty acids on chronic kidney disease-associated pruritus: a literature review. Adv Pharm Bull. 2016;6(4):509-514. doi:10.15171/apb.2016.064

158. Kim KH, Lee MS, Choi SM. Acupuncture for treating uremic pruritus in patients with end-stage renal disease: a systematic review. $J$ Pain Symptom Manage. 2010;40(1):117-125. doi:10.1016/j.jpainsymman.2009.11.325 
159. Xiong W, He FF, You RY, et al. Acupuncture application in chronic kidney disease and its potential mechanisms. $\mathrm{Am}$ $J \quad$ Chin Med. 2018;46(6):1169-1185. doi:10.1142/ S0192415X18500611

160. Kim KH, Lee MS, Kim TH, Kang JW, Choi TY, Lee JD. Acupuncture and related interventions for symptoms of chronic kidney disease. Cochrane Database Syst Rev. 2016;6:CD009440. doi:10.1002/14651858.CD009440.pub2
161. Badiee Aval S, Ravanshad Y, Azarfar A, Mehrad-Majd H, Torabi S, Ravanshad S. A systematic review and meta-analysis of using acupuncture and acupressure for uremic pruritus. Iran J Kidney Dis. 2018;12(2):78-83.

162. Martin CE, Clotet-Freixas S, Farragher JF, Hundemer GL. Have we just scratched the surface? A narrative review of uremic pruritus in 2020. Can J Kidney Health Dis. 2020;7:2054358120954024. doi:10.1177/2054358120954024

\section{Publish your work in this journal}

Therapeutics and Clinical Risk Management is an international, peerreviewed journal of clinical therapeutics and risk management, focusing on concise rapid reporting of clinical studies in all therapeutic areas, outcomes, safety, and programs for the effective, safe, and sustained use of medicines. This journal is indexed on PubMed Central, CAS,
EMBase, Scopus and the Elsevier Bibliographic databases. The manuscript management system is completely online and includes a very quick and fair peer-review system, which is all easy to use. Visit http://www.dovepress.com/testimonials.php to read real quotes from published authors. 